\title{
"COMING INTO THE WORLD: FROM SPIRITS TO THE SPIRIT". THE FIRST CHILDHOOD MUSEUM IN ROMANIA
}

\author{
Anamaria Iuga \\ PhD, Head of the Ethnology Studies Department \\ National Museum of the Romanian Peasant \\ Fellow 2019-2020 New Europe College \\ Institute for Advanced Study, Romania \\ anaiuga@gmail.com
}

\begin{abstract}
The present paper follows the National Museum of the Romanian Peasant (Romania) in its endeavour to display the Virtual Museum of Childhood. The context prior to exhibiting material and intangible heritage related to childhood is analysed, and the curatorial challenges of this project are mentioned. This article also refers to the museum's activities dedicated to childbirth (exhibitions, cultural activities), from 1990 to the present day, but it especially focuses on the first exhibition of the Museum of Childhood, "Coming into the world: From spirits to the Spirit", dedicated to birth.
\end{abstract}

Keywords: childbirth, exhibition, intangible heritage, Museum of Childhood, Museum of the Romanian Peasant

\section{INTRODUCTION}

As Horia Bernea, ${ }^{1}$ the creator of the Museum of the Romanian Peasant (Bucharest, Romania), ${ }^{2}$ stated, this institution is "a museum of context, of relation (between objects and space), of rhythm" (Bernea 2001: 71), an unconventional museum, defined by "a perpetually prolific state continuously allowing for new beginnings" (ibid.: 82). This is a perfect definition for a museum which was reborn in 1990, in a building meant to be a village art museum but repurposed by the communist regime to be an ideological museum (Popovăț 1999). The Museum of the Romanian Peasant exhibits and speaks about the traditional world, which "did not 'produce' objects, but begot" (Bernea 2001: 123) - to sum up, a museum where "genesis" can be found at different levels, from the appearance of a new institution to exhibiting intangible heritage related to childbirth, and to creating a new museum dedicated to childhood, as shown below. 
To start from the very beginning, I should first mention that the researchers of the Museum of the Romanian Peasant have always shown a distinct interest in the activities involving children or in events related to childhood, Ioana Popescu, ${ }^{3}$ ethnologist and part of Horia Bernea's founding team, being the consistent promoter of this curatorial focus. Ioana Popescu and Irina Nicolau ${ }^{4}$ were a good team in this research area even since they were both working at the Institute of Folklore (Romanian Academy) (Popescu \& Nicolau 1983). Their interest in studying the cultural heritage referring to childhood and especially to childbirth was so strong that Irina Nicolau once said: "If we are to be experts in something, I'd rather be one in childbirth" (I.P. ${ }^{5}$. Anyhow, it was definitely Ioana Popescu's keenness for childhood that started this research interest: "for years she [Ioana] was haunted by a museological approach to children" (Irina Nicolau in Bernea 2001: 34). However, the two researchers intended to open a "Copilarium" (Childarium) (I.P.), a space dedicated to children - an idea which led to an original cultural project and to opening the Virtual Museum of Childhood ${ }^{6}$ in 2013.

The present paper intends to explore the history of cultural and research approaches related to childhood and childbirth, carried out by the museum. The resources I have used range from published materials (Bernea 2001; Popescu et al. 1991; Martor 2013) to my own experience within the European project Childhood: Remains and Heritage. ${ }^{7}$ Yet, the most important source of information is given by Ioana Popescu, interviewed on 17 February 2020. The ethnologist speaks about the activities carried out at the museum from its very beginning, activities related to events or exhibitions for or about children or childhood. The interview proves a constant interest in this topic as well as the challenges they faced.

\section{MUSEUM, CHILDHOOD, AND BIRTH}

When the museum was initiated, by chance or by hazard, or I don't know how, the first small team of the museum, from the first day of the museum, was mainly made up of women. Most of them women around 30 years of age. So, they were somehow on their way up in their career, at the same time having children, young children ... it felt as if you were stepping on a minefield, as you were not good enough at either museum work or parenting, everything was new. And then, somehow, the solution was to combine parenting with museum development. (I.P.)

These memories were revisited at the very beginning of the interview, emphasising the tight connection between the opening of the museum and children- 
related activities. Moreover, as Ioana remembers, in 1990-1991, children were regularly present in daily activities: "Children's touch was in almost everything we were doing, this was how things were working" (I.P.).

The beginning of the museum is defined by activities dedicated to children. For instance, as the museum was not yet open at the beginning of the year 1990, and in order to attract the attention of the public, the director Horia Bernea decided to open it up to the public with an exhibition hosted by Galeriile Orizont ${ }^{8}$ in the heart of Bucharest. The first one was dedicated to clay toys, "having as the main character a mother holding a baby" (I.P.). It is an important detail considering that the museum was first opening up to the public exhibiting objects dedicated to children. The first creativity workshops (see Oprea-Minoiu et al. 2017) were also organised at that time, as there was a special room for children's creative activities. As a novel and playful detail, the room featured a poster at the entrance "which read, to parents' dismay, 'Access of parents unattended by children strictly forbidden" (I.P.). ${ }^{9}$

While the first public exhibition was dedicated to children, the first temporary exhibition opened in the museum building in $1991,{ }^{10}$ the second year of its existence, and was dedicated to childbirth, another significant gesture in emphasising the interest in the topic of childhood (Fig. 1). The exhibition titled Prunc (Infant) was a novel one, "uncommon even for the ethnographic museology of today, because there were a number of beliefs [exposed] in it. It was a trial, a successful one I would say, to exhibit intangible culture" (I.P.). Irina Nicolau explained:

[It was about] exhibiting a hypothesis hard to digest and even harder to communicate: in its first weeks, maternity is a terrible experience. The child, coming from who knows where, disputed by both people and evil ghosts... We wanted to talk about the horror of childbirth, about a mother's fears and her care for the baby. (Bernea 2001: 37)

The exhibition mostly highlighted the intangible heritage "using tiny signs, tiny handwriting, a detail on the floor, things like these, impactful things, which made you understand a certain belief" (I.P.). The beliefs presented in this exhibition (see Fig. 2 to perceive the way they were exhibited) covered various topics: interdictions during pregnancy, childbirth, signs about the future of the child, baby's first bath, choosing the child's name, practices referring to healing childhood diseases, etc. As Irina Nicolau recalled, one of Horia Bernea's requests referred to including the ritual of baptism, meant to bring peace in the unstable postnatal period: "He came and said: how do you think there can be so much darkness without the deliverance of baptism? And right away he started to paint the 'iconostasis' for the birth in Spirit” (Irina Nicolau in Bernea 2001: 38). 


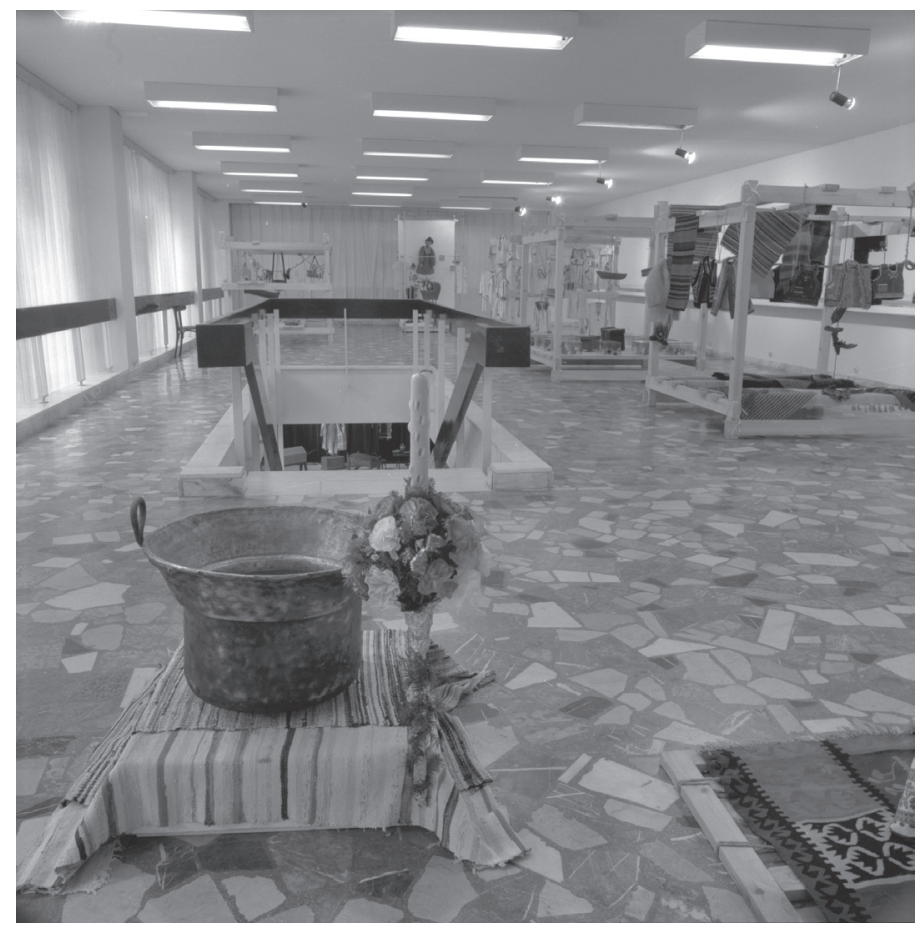

Figure 1. Overview of the exhibition Prunc (Infant), 1991. Photograph by Marius Caraman, in possession of the Ethnological Archive of the National Museum of the Romanian Peasant.

Birthing beliefs were also covered by the catalogue titled Prunc (Popescu et al. 1991), published in "200 numbered copies on white paper in brown ink" (ibid.: ii). The publication was illustrated with children's drawings inspired by icons painted on glass, especially those dedicated to the Nativity of Jesus.

Referring to material culture, "the exhibition displayed only few valuable objects, to put it this way ... The exhibition was conceived as a route running between shown and hidden, somehow you saw some things partially, and you had to guess some things behind some panels, things that you could not see, because, I repeat, we were playing with the immaterial ... Regarding the objects displayed, if I remember well, there were 2-3 clay toys, some thick rural swaddling clothes which had nothing to do with our perception of urban babies, wearing white and lacy outfits ... meant to shock somehow, to show that things could be totally different." (I.P.)

Anyway, from the very entrance visitors were overwhelmed by "dark" beliefs regarding giving birth. The first thing visible when entering the exhibition was "a large piece of paper, in ugly and striking writing, ugly indeed, conspicuously 


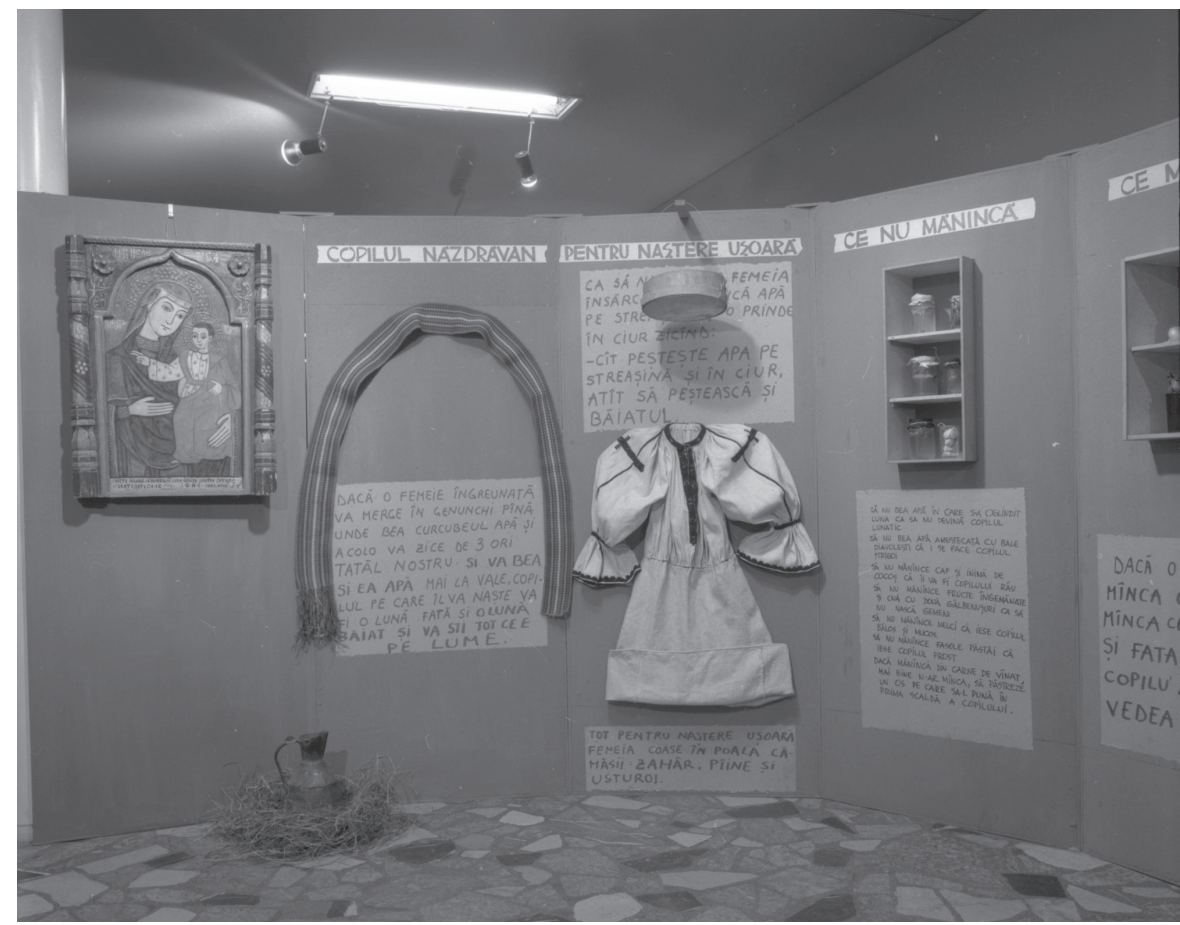

Figure 2. Detail from the exhibition Prunc (Infant), 1991. Photograph by Marius Caraman, in possession of the Ethnological Archive of the National Museum of the Romanian Peasant. Texts from the image, from left to right: "FOR A SPECIAL CHILD. If a pregnant woman would go on her knees to the place the rainbow starts and would say three times Holy Father and drink water, the child she delivers will be one month a girl, and one month a boy, and will know all there is to know in this world." "FOR AN EASY BIRTH. To have an easy birth, the pregnant woman should catch the water that falls from the rims of the house and the sieve, and say: As the water does not remain on the rims of the house and in the sieve, the same will happen to the baby to be born. Also, for an easy birth, the women would sew into the lap of the shirt sugar, bread, and garlic." WHAT PREGNANT WOMEN DO NOT EAT [fragments]. She should not drink water that mirrored the moon, for the child not to be lunatic. She should not eat the head and the heart of a rooster, because the baby will be evil. She should not eat twinned fruits, or eggs with two yolks, or she would have twins. Etc."

ugly, which read: 'A woman without children is running around wildly and knows nothing about God"' (I.P.). Thus, the audience was sifted: if the visitor was a woman who did not have children, after reading this first text she "turned around and left" (I.P.).

Once this warning was walked past, the exhibition opened "with a narrow red area which made you think about the womb" (Irina Nicolau in Bernea 2001: 37). The "abortion corner" was among the first things that could be seen. It was a "shabby rag stained with red paint, meaning blood ... So, it was something 
dirty, dreadful, which was in your way, and could not be avoided" (I.P.). Here are Irina Nicolau's memories:

I can't remember who had the idea of throwing somewhere next to a wall a rag stained with ink 'blood'. At the opening, our friends were trying to hide the rag, kicking it around. The second day we glued it to the floor. Enough! During labour you cannot ignore completely the blood, lochia, the placenta, the navel. This is how people are born, producing some residues, and peasants were in the know about them. (Bernea 2001: 37)

The public had contradictory reactions because "the exhibition was so freshly authentic, so honest that it bothered many people" (I.P.). Undoubtedly, this first exhibition dedicated to childbirth echoed further on, being one of the main sources of inspiration for the exhibition opening the Museum of Childhood years later.

Yet, apart from other events dedicated to children and childhood, ${ }^{11}$ there are two more types of activities worth mentioning, chronologically speaking, in relation to the theme of giving birth. As Ioana recalls:

The next step in the relationship with [the topic of] childbirth, at least in my case, was a surprising request. Médecins Sans Frontières urgently requested a specialist from the Museum of the Peasant to deliver two lectures ... on birth beliefs and practices in Romania. (I.P.)

The talks were given by Ioana and, as she remembers, "[the doctors] were listening carefully, were writing down, interrupting me and asking questions about a lot of details that I wasn't aware of. Details related to gestures, to sequencing: if they spit before or during uttering the charm, things like this. And they would exclaim: Ah! That's why they didn't allow us to do that!" (I.P.)

This experience speaks not only about cultural differences but also about the practical role of ethnology.

Later on, in the 1990s, the programme called "Missionary Museum" was launched. It entailed that the specialists were to go to "places less visited by the museum and to leave something behind: a small exhibition, or a talk, a performance, a gesture, something" (I.P.). Most of the time they would leave behind the brochure titled Kind thoughts with texts of "Romanian and Orthodox wisdom mainly dedicated to maternity. [Irina] would have liked to place a brochure on each bedside cabinet in a maternity ward." (I.P.)

Therefore, the beginning of the museum is linked to the interest in children, and especially to the interest in the traditional culture of giving birth. Thus, the museum is also born out of the endeavour of the researchers who 
are "specialists in childbirth" (I.P.), generating an important direction which, among other things, led to the opening of the Virtual Museum of Childhood.

\section{THE BIRTH OF THE MUSEUM OF CHILDHOOD}

The Museum of Childhood was the natural corollary of the constant interest in this direction. As a result of an EU-funded cultural project, in partnership with other European institutions, this museum was meant to fill a lack in the Romanian cultural landscape, namely the absence of a museum dedicated to childhood, which "will cover this period entirely - meaning childhood in everyday life, childhood with celebrations, childhood with diseases, health, everything you can think of, childhood with children's oral productions, childhood with community's products dedicated to children" (I.P.). Therefore, in 2013, the Museum of Childhood was inaugurated online, as there was no physical space to host such a museum. After a year of research and documentation, a series of six temporary exhibitions were opened. Before closing, each exhibition was photographed, using the technique of panning and turned into a virtual museum room. There are six such exhibition spaces, ${ }^{12}$ one dedicated to creativity workshops organised within the cultural project (Room 7), and another one hosting a travelling exhibition (Room 8) (see also Passima 2013), organised as a summary of the six temporary exhibitions and opened in seven European cities. ${ }^{13} \mathrm{~A}$ unique aspect of this project is that it brought up a larger cultural dialogue, extended over the European cultural area, not restricted to the Romanian one. Therefore, in each exhibition there was "a slight detail, a tiny highlight, a detail of western culture; to find out whether things are similar, how similar or different they are" (I.P.).

Displaying intangible heritage was again one of the challenges; yet, unlike 1991, there was a new technology to be used this time. Consequently, together with objects, images, and written texts, audio materials were also displayed: spoken fragments, stories, part of interviews and lullabies, but also videos present in both physical and virtual exhibitions. Regarding childhood's material culture, the objects from the museum's collections were brought from home by the people involved in this project:

Some of the objects had been collected by volunteers, we brought some things, and others were bought for this very exhibition, because it needed to have elements from other cultural European areas, especially past and present-day ones. ... And, in order to show these things, we went shopping at IKEA, and all sorts of pan-European shops. (I.P.) 


\section{“FROM SPIRITS TO THE SPIRIT": ABOUT BIRTH AT THE MUSEUM OF CHILDHOOD}

As expected, the first exhibition that opened at the Museum of Childhood was dedicated to childbirth.

[It is] a discourse about gestation: the future child appears from nowhere into the mother's womb, ... then his / her organic growth inside the mother's body, the bloody, hurtful and tormented exit; how all these disrupt the quiet, peaceful, serene village. And the village perceives this time as haunted. ... So, everybody focuses on attracting the good forces and on protecting against the evil ones. These are the spirits. And therefore, I said ... from the spirits to the Spirit, as after birth, soon after birth ... baptism is performed. And baptism calms down everything. (I.P.)

The exhibition mainly displayed objects: some traditional, found in the museum's collection, but also modern, contemporary ones (Fig. 3). Many photographs were also shown: from the archives of our partner institutions, but also from our volunteers' personal archives. Moreover, fragments of the intangible heritage (handwritten texts about old rural beliefs, and also about new contemporary Romanian or European beliefs or practices hung or glued to the wall) were also present.

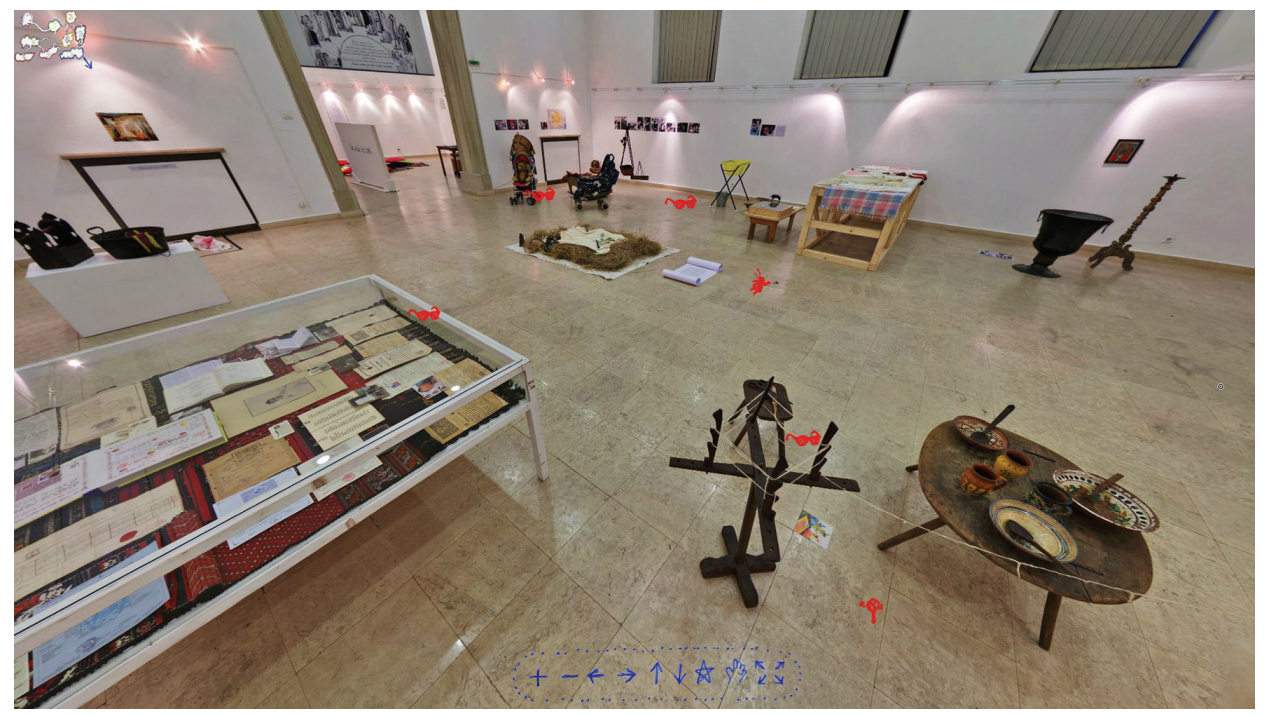

Figure 3. Overview of the exhibition "Coming into the world: From spirits to the Spirit", 2012. Print screen of the virtual museum (http: / / www.childhoodmuseum360.eu/ro). 
Yet, in order to present the exhibition, it is necessary to "walk" through it, mentioning only the most important elements. It starts outside: on the door there is a framed photograph of a door on which a pair of red tassels is stuck with a knife. It was the sign placed by the midwives on the house door, for giving birth easily.

Once stepping over the threshold, we are welcomed by the question "Where do children come from?" (Fig. 4), which sends us to the beliefs regarding pre-birth period, "when children do not really exist, but in fact they are very present in the behaviour of the entire village. They influence the way of living and the way of speaking: suddenly, some words are no longer used and people choose more carefully what they say" (I.P.). This phase is represented by a mask hanging from the ceiling, a symbol of the evil spirits threatening the intrauterine baby, and also by a woman's gown next to it. A short prayer that pregnant women always had with them for protection, as well as all sorts of plants (basil, wormwood, garlic, etc.), also for protective reasons, are sewn on this piece of clothing. The answer to the first question is somehow given by the text handwritten in spiral: "The child in a cabbage, brought by a stork, bought with a sieve of corn flour, dreamt in a flower, brought by water." The exhibition route passes then through an archway featuring an image of life phases as they were represented in the nineteenth century. Childhood is assigned the area under the first step, the message being that, in fact, childhood at the time (nineteenth century),

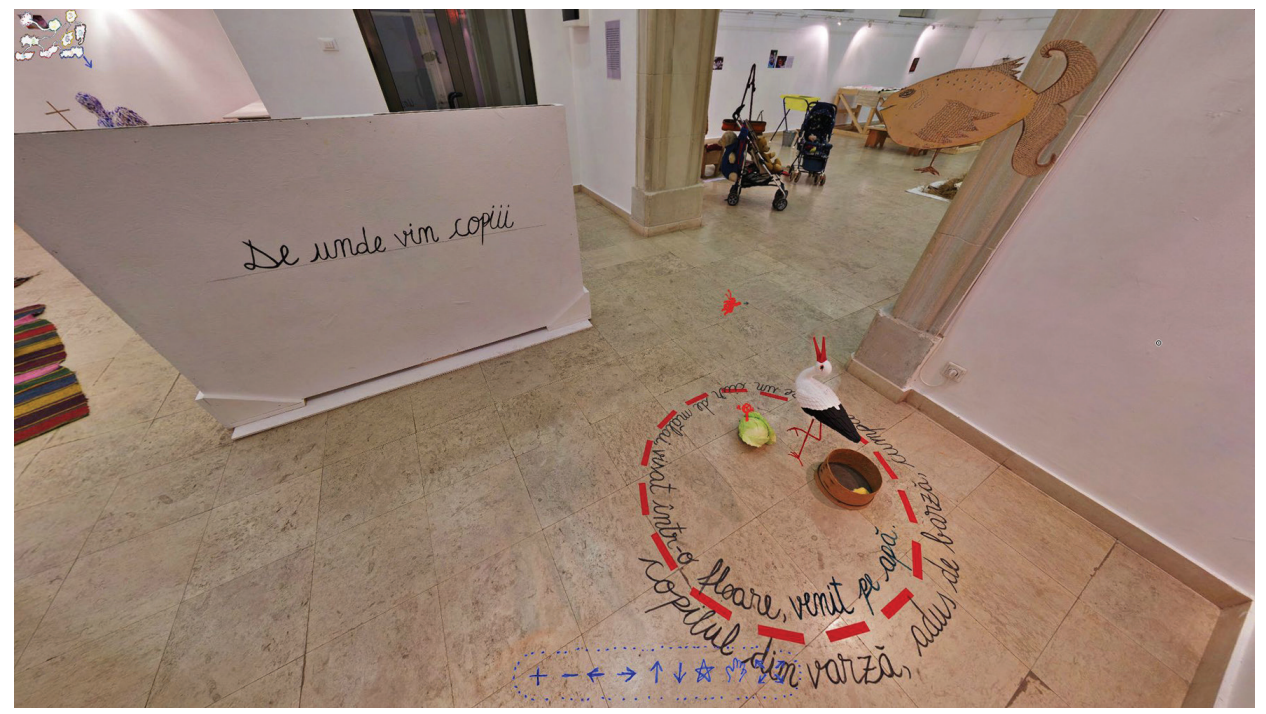

Figure 4. Detail of the exhibition "Coming into the world: From spirits to the Spirit", 2012. Print screen of the virtual museum (http:/ / www.childhoodmuseum360.eu/ro). 
and as the researches in the villages point out, was not given too much attention and space; for example, at a very early age, children would help in the household labours. Thus, it was considered by the curators to be an invention of the modern world.

When entering the second room, attention focuses on its centre. Here the objects present the act of giving birth, which used to take place on a heap of hay, with the woman surrounded by symbolic objects (the father's shirt, an axe placed under the sheets or a bell, as it is believed that strong sounds chase the evil spirits away) meant to ensure an easy labour (Fig. 5). The explanatory text framed as an inscription on a large piece of paper mentions other similar practices and beliefs: "In order to hurry the delivery, the midwife would cut the woman's waistband, in order to remove the baby's obstacles, or would pour water out of an old pot. Could there be a connection between the pot with water and the present pool recommended for painless childbirth?" The exhibition is visually dominated by an icon painted on wood representing Mary, Mother of God, holding the Infant Jesus. In its simplicity, it speaks about maternity.

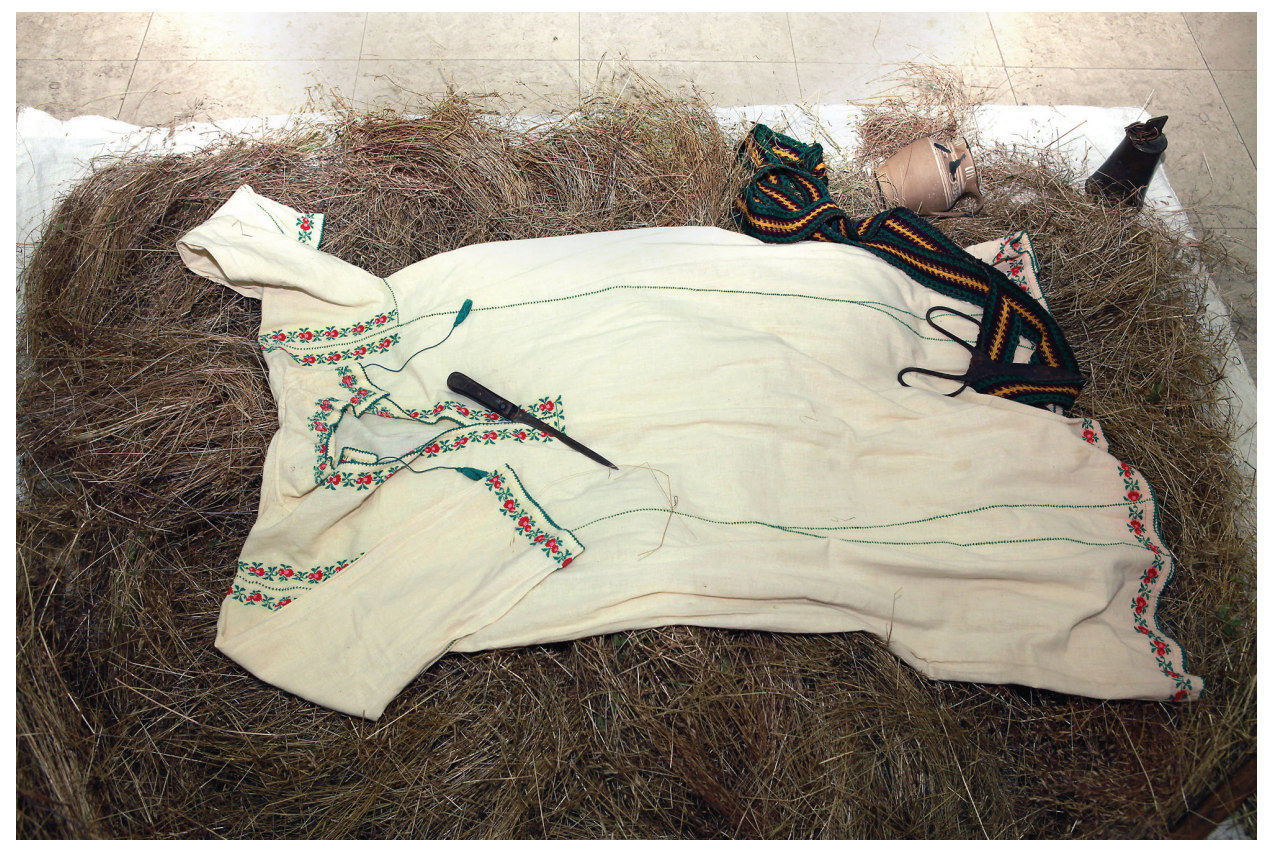

Figure 5. Detail of the exhibition "Coming into the world: From spirits to the Spirit", 2012. Photograph by Marius Caraman, in possession of the Ethnological Archive of the National Museum of the Romanian Peasant. 
On the right side of the exhibition wall other phases prior to birth are displayed. Using the idea of the bloody rag from the 1991 exhibition titled Prunc (Infant), the first thing that can be seen on the right side is such a cloth placed on the floor, in the corner dedicated to abortion. However, right next to it the exhibition goes back to the pre-birth beliefs, namely the practices related to guessing or influencing the gender of the baby. ${ }^{14}$ The texts also refer to contemporary practices, including ultrasound scan. The table with documents related to birth, displayed next, is a good example of combining the old and the new: old and new birth certificates, photos of babies, even a baby diary (Fig. 6). All these talk about the institutionalisation of childbirth and about the contemporary need to produce archive documents. Another comparison between traditional beliefs and pan-European beliefs promoted in mass media (e.g. Disney animated feature film Sleeping Beauty) refers to the Fates in relation to the three fairies from a different area. The still-living practice of placing a mug with water and a slice of bread on the maternity ward window sill to please the Fates, followed by displaying Aromanian ${ }^{15}$ women's simple gesture of placing a loaf of bread

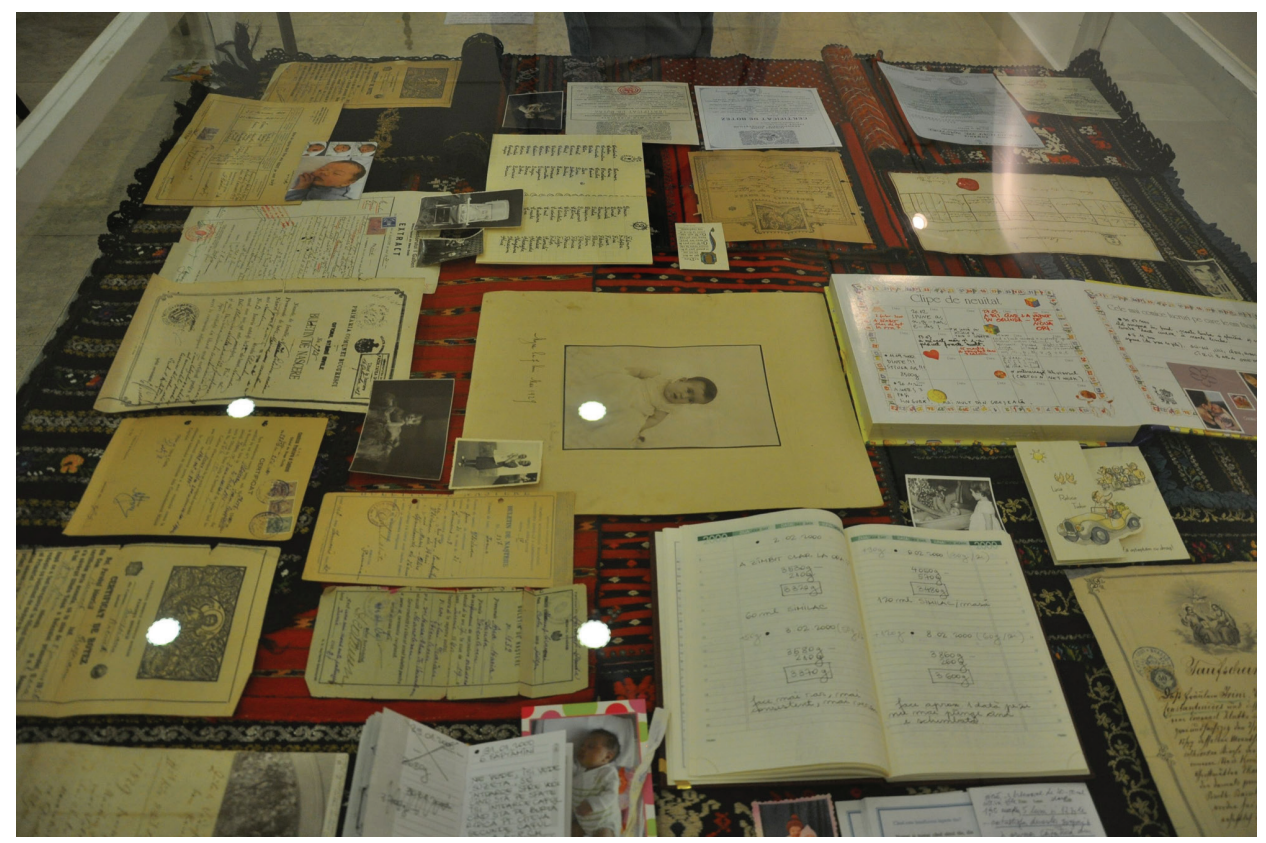

Figure 6. Detail of the exhibition "Coming into the world: From spirits to the Spirit", 2012. Photograph by Marius Caraman, in possession of the Ethnological Archive of the National Museum of the Romanian Peasant. 
into the cradle on the first night after giving birth is also mentioned. Further on, there is a corner dedicated to maternity. There are relevant photographs here, like the one that was taken in a "communist maternity", referring to the abortion ban and to the generation of the "post-decree babies"; there are also some suggestive objects (a baby scale), but also texts of volunteers which appeal to their families' memories in their parents' accounts about the day they were born.

In another part of the room, an installation with old and new objects refers to breast feeding: a few modern baby bottles in contrast to a note saying that "the only baby bottle of the village was the wet-nurse", next to some clay figures representing maternity. An almost iconic object is the shirt with two crosses sewn on the chest. It speaks about the belief that mother's milk could be easily spoilt or stolen by a "milk strigoi" ${ }^{16}$ The two crosses were meant to prevent this from happening.

The next important section is dedicated to baptism - the second birth - into the Holy Spirit. Apart from the religious ritual objects, there are also baby clothes offered by godparents on the baptism day. The clothes displayed were gathered from volunteers, thus their memories bring the exhibition discourse to the present. A small table nearby displays the small gifts given to the guests at the baptising ceremony (mărturii). Next to them there is a wooden bathtub, with its contemporary plastic version, containing small symbolic objects placed in the baby's first bath, such as sugar and honey for the baby's life to be sweet; flour and wheat grains to be prosperous; a coin to provide for richness; flowers and basils for their beauty. The tour in this room finishes with old and new swings, suspended or fixed, back baskets and all sorts of prams and strollers. All these exhibits are illustrated by archive pictures of women holding or carrying children and by some lullabies from the museum's archive, played by a loudspeaker. They are all included in the virtual tour; all you need is to push the button.

The exhibition ends with presenting a dramatic moment, the premature death. "The climax of the first exhibition was embodied in the material and palpable expression of the question 'Where do babies go?"' (Marinescu 2013: 160 ). The answer is given by the angel created and offered by a Romanian artist, Silvia Radu, ${ }^{17}$ a good friend of the museum. The statue points towards the wall displaying a baby's blouse with a cut at the back, reminding of a belief referring to deceased infants. The end is so dramatic, and it touched so many people that it triggered emotional comments from visitors: "I was about to leave the exhibition hall when I saw an object I had missed. The little shirt cut in the back so that the dead baby's wings could grow is simply breath-taking!" (Marinescu 2013: 160). 
The exhibition seen "as a bridge between old and new, a connection between past and present, between the way in which our grandparents were welcomed into this world and the way in which we welcome our own children today" (Marinescu 2013: 160) is a circular course - a course which starts in the "unknown world" where children come from, "shared by both the unborn and the deceased" (I.P.), and which ends with the same world, maybe having a less clear shape, where dead children go as angels. In all these stages, from the protection in the intrauterine period to birth and, later, to the spiritual birth (baptism), rituals, beliefs, and old as well as new practices mark the fragile existence of a new-born baby. Therefore, the curators working on this exhibition selected and exhibited the beliefs considered more relevant, always finding the elements in contemporary culture and in the European area that, from the beginning of the project, they wanted to attach to traditional Romanian culture.

\section{CONCLUSIONS}

One of the purposes of the project Childhood: Remains and Heritage was to awaken some of the public's feelings, as the exhibition was supposed to be "more than a discovery and experience, how shall I put it, [to produce] emotional feedback [in the visitors]" (I.P.). And this happened from the very first exhibition dedicated to childbirth until the last one about games and toys, as "all the museum developed step by step, existed in real form, and then we got to check the reaction of the public" (I.P.). Visitors would leave their comments in a special notebook (Marinescu 2013) and online, on the blog ${ }^{18}$ created back then, at the request of the volunteers. Our public played along. It took only an object, a thought, a text to make them remember their own childhood.

Ioana Popescu recalls:

If childhood moments are situated rather far away in time from the present adulthood, then their remembrance might become a truly exotic journey and the objects that populated that world of the beginning might function as mystery-bearing relics, as triggers of cultural curiosity and surprise. (Popescu \& Bădică 2013: 9)

Childbirth will always be in the stories told by the people close to us and shaped around the objects kept as family treasures. Therefore, for the team of this project, who unexpectedly and surprisingly had the perks of "childlike behaviour", it was important not only to exhibit the objects sheltered by the museum, but also to include a segment of contemporary life, in volunteers' objects and stories, in the photographs from the present or recent past of all the people involved in this 
project. As the exhibitions revolved around the intangible heritage, a relevant role was played by the volunteers' accounts about the beginning of their life, accounts which were recorded, transcribed, and included in the archive of the project. These recordings are an endless source of information and also of joy.

The first exhibition of the Childhood Museum dedicated to birth and continuing all the activities of the Museum of the Romanian Peasant, from its very beginning, was a good start and an example to be followed by the next exhibitions, always including these fragments of contemporary life lived by our volunteers. The success of the Childhood Museum also relies on the fact that it is still in the public eye because of its mentioning in the Romanian language and literature textbook for the 4th grade (Radu \& Jeler 2016), which shows how much the Romanian cultural area needed this approach.

\section{NOTES}

1 Horia Bernea (1938-2000), painter and director of the Museum of the Romanian Peasant from 1990 to 2000.

2 The Museum of the Romanian Peasant, named the National Museum of the Romanian Peasant in 2006, is located in Bucharest, Romania. It is a museum of cultural anthropology dedicated to the peasants' world. The museum was founded in 1990, in the same building that was built in 1912-1941 to host a traditional art museum, but then, in 1953, its collections were moved elsewhere, and in the same building the Museum of the Communist Party was opened (see http://www.muzeultaranuluiroman. ro, last accessed on 15 September 2020).

3 Ioana Popescu (b. 1949), ethnologist and researcher at the Institute of Folklore of the Romanian Academy until 1990. In 1990, she joined the founding team of the Museum of the Romanian Peasant, later coordinating the Department of Ethnological Research.

4 Irina Nicolau (1946-2002), ethnologist and researcher at the Institute of Folklore of the Romanian Academy until 1990. In 1990, she joined Horia Bernea's team to create the Museum of the Romanian Peasant.

5 The excerpts from the interview with Ioana Popescu (aged 71, interviewed in Bucharest on 17 February 2020) are quoted followed by her initials, in order to simplify the endnotes.

6 The Virtual Museum of Childhood (http://www.childhoodmuseum360.eu/ro) is the final result of the project Childhood: Remains and Heritage, carried out by the National Museum of the Romanian Peasant in partnership with the Museum of Lebork (Poland), Romanian Cultural Institute (Romania), and the Association ARTEES (France), financed with the support of the European Union's Culture Programme, between 2011 and 2013. 
7 The team of the National Museum of the Romanian Peasant working on creating the virtual museum: Ioana Popescu (coordinator of the cultural project), Rodica Marinescu, Anamaria Iuga, Raluca Magda Oprea-Minoiu, Liliana Passima, and Cosmin Manolache, together with a team of volunteers of whom I would mention Anca-Maria Pănoiu, Valentina Bâcu, Ioana Barbara Tănase, Simona Gal, and Ioana Corduneanu.

8 The first exhibition was displayed in a different location, because the museum building was being refurbished: the old collection was being packed up (the Museum of the Communist Party) and the space was being prepared for the new exhibition. Back then, Galeriile Orizont belonged to the Union of the Visual Artists in Bucharest.

9 The first attempt to set up a workshop for children failed in "a perfect implosion, but the result was reached, meaning that it was a space where children were totally free and had their creativity stimulated" (I.P.).

${ }^{10}$ Considering all exhibitions organised at the museum between 1990 and 1991, the exhibition Infant is the sixth one, the second one was staged in 1991 (see Bernea 2001: 176).

${ }^{11}$ For instance, the exhibitions displaying archive documents of children presented within the programme "The Image Hall" or the programme "The Village School”, which later led to creativity workshops (Oprea-Minoiu et al. 2017).

12 The first exhibition room under the heading "Coming into the world: From spirits to the Spirit" is dedicated to childbirth. Room 2 is dedicated to children's world under the heading "The small world of the small". Room 3 is about things used by children, "Small things for large needs". Room 4 is about what children do to discover the world around: "Discovering the world, at home and at school". Room 5 is dedicated to childhood challenges: "Relations with the grown-up world", and room 6 is dedicated to children's toys: "Creating the world: Games and toys".

${ }^{13}$ Paris, London, Madrid, Rome, Stockholm, Warsaw, and Lebork, the city of our partner museum. In each of these locations, the exhibition was enriched by at least one added element, a local object, no matter how small, thus growing like an enchanted child in a fairy tale.

14 "If the woman sits on a winder, a boy will be born, if she sits on a tub, a girl will be born" (text in the exhibition).

15 The Aromanians are an ethnic group living in the Balkans (northern and central Greece, southern Romania, central and southern Albania, north Macedonia and southwest Bulgaria), and speaking a Latin-derived language, considered to be a dialect of the Romanian language.

${ }^{16}$ In Romanian villages there is a belief that milk can be stolen by the "milk strigoi" (milk vampires), from animals but also from young mothers.

${ }^{17}$ Silvia Radu (b. 1935) is a Romanian visual artist, ceramist, and painter.

${ }^{18}$ See http://copilariamuzeultaranului.blogspot.com/, last accessed on 15 September 2020. 


\section{REFERENCES}

Bernea, Horia 2001. Cîteva gînduri despre muzeu, cantități, materialitate și încrucișare. [A Few Thoughts about Museum, Quantities, Materiality, and Intersections.] Irina Nicolau \& Carmen Huluță Dosar sentimental. [Sentimental Files.] Bucharest: Ars Docendi.

Marinescu, Rodica 2013. The Childhood Museum - Guestbook. Martor, Vol. 18, pp. 159-162. Available at http://martor.muzeultaranuluiroman.ro/wp-content/ uploads/2015/07/marinescu_site.pdf, last accessed on 15 September 2020.

Martor 2013. Remembering Childhood. Vol. 18. Available at http://martor. muzeultaranuluiroman.ro/archive/revista-martor-nr-18-din-2013/, last accessed on 15 September 2020.

Oprea-Minoiu, Raluca \& Manolache, Cosmin \& Pascu, Ana \& Voicilă, Ciprian \& Grigorescu, Ruxandra \& Florian, Mirela \& Iordan, Beatrice \& Stareș, Lidia \& Bâcu, Valentina 2017. Atelierul de creativitate: A Sentimental Dossier. Martor, Vol. 22, pp. 167-180. Available at https://journals.indexcopernicus.com/api/file/ viewByFileId/197599.pdf, last accessed on 15 September 2020.

Passima, Lila 2013. Childhood: The World Seen through Binoculars. Martor, Vol. 18, pp. 137-160. Available at http://martor.muzeultaranuluiroman.ro/wp-content/ uploads/2015/07/passima_site.pdf, last accessed on 15 September 2020.

Popescu, Ioana \& Bădică, Simina 2013. Two Introductions. Martor, Vol. 18, pp. 9-15. Available at http://martor.muzeultaranuluiroman.ro/wp-content/uploads/2015/07/ popescu_badica_site.pdf, last accessed on 15 September 2020.

Popescu, Ioana \& Nicolau, Irina 1983. Introducere în etnologia primei copilării. [Introduction in the Ethnology of the Early Childhood.] Revista de etnografie și folclor, Vol. 28, No. 1, pp. 46-61.

Popescu, Ioana \& Nicolau, Irina \& Anghelescu, Șerban \& Petrescu Ileana 1991. Prunc. [Infant.] Bucharest: Muzeul Țăranului Român.

Popovăț, Petre 1999. Muzeul de la Șosea. [The Museum Close to the Driveway.] Martor, Vol. 4, Supplement. Available at http://martor.muzeultaranuluiroman.ro/ wp-content/uploads/2017/12/revista-martor-04-1999-supliment.pdf, last accessed on 15 September 2020.

Radu, Alina \& Jeler, Roxana 2016. Limba și literatura română: manual pentru clasa a IV-a. [Romanian Language and Literature: Textbook for the 4th Grade.] Bucharest: Art.

Anamaria Iuga, $\mathrm{PhD}$, is Head of the Ethnology Studies Department at the National Museum of the Romanian Peasant, Bucharest, Romania. She is also a New Europe College Fellow (2019-2020). Her field of research includes the dynamic of material culture and intangible heritage as well as traditional ecological knowledge.

anaiuga@gmail.com 